\title{
Tectonomagnetic study in the eastern part of Hokkaido, NE Japan (II): Magnetic fields related with the 2003 Tokachi-oki earthquake and the 2004 Kushiro-oki earthquake
}

\author{
Yasunori Nishida ${ }^{1}$, Mitsuru Utsugi ${ }^{2}$, and Toru Mogi ${ }^{1}$ \\ ${ }^{1}$ Institute of Seismology and Volcanology, Faculty of Science, Hokkaido University, Sapporo 060-0810, Japan \\ ${ }^{2}$ Institute for Geothermal Sciences, Graduate School of Science, Kyoto University, Kumamoto 869-1404, Japan \\ (Received February 21, 2007; Revised August 6, 2007; Accepted September 27, 2007; Online published November 30, 2007)
}

\begin{abstract}
We examined short-term geomagnetic changes related with the 2003 Tokachi-oki earthquake $(M$ 8.0) and the 2004 Kushiro-oki earthquake (M 7.1) in Hokkaido, Japan. However, we could not find the precursory and coseismic signals above several $\mathrm{nT}$ at a magnetic station whose epicentral distances were about $120 \mathrm{~km}$ and $50 \mathrm{~km}$, respectively. Model calculations showed that co-seismic piezomagnetic fields did not amount to $1 \mathrm{nT}$ at the station in both cases when we assumed the relevant fault parameters, in-situ Curie temperature depth, subsurface magnetic structure and stress sensitivity of rocks. Therefore, it may be reasonable that we could not detect the piezomagnetic signals at the station. We also made model calculations to forecast the piezomagnetic amplitudes caused by $M 7.9$ and $M 8.5$ earthquakes which have been expected to occur along the southern Kurile trench in the future. The model calculations reveal the piezomagnetic fields up to about $-4 \mathrm{nT}$ and $-7 \mathrm{nT}$ are expected in the eastern part of the Hokkaido island for the $M 7.9$ and $M 8.5$ earthquakes respectively, encouraging magnetic observations hereafter.
\end{abstract}

Key words: Piezomagnetism, co-seismic signal, detectability of piezomagnetic signal.

\section{Introduction}

We had made magnetic observations at six stations in the eastern part of Hokkaido, Japan, until 1999. The observations depicted that anomalously large secular changes of the geomagnetic total force (about $1 \mathrm{nT} /$ year) have lasted at least for about 3 to 30 years (depending on the period of observations) in the Pacific coast region of the eastern part of Hokkaido (Nishida et al., 2004). Large amplitudes of the geomagnetic anomalies up to about $\pm 1,700 \mathrm{nT}$ are characteristic features in this region, suggesting the existence of highly magnetized rocks. The magnetic structure producing of the large magnetic anomalies was modeled by composition of 3-D rectangular magnetized blocks from near surface to about $10 \mathrm{~km}$ depth, assuming that each block has uniform magnetization $(8 \sim 10 \mathrm{~A} / \mathrm{m})$ parallel to the ambient geomagnetic field. Although the resolution of the deeper structure is poor and by no means unique in the present forward model calculation, the existence of highly magnetized bodies is probable from shallow depth to about $10 \mathrm{~km}$. Only the horizontal projection of calculated magnetized blocks is shown by a shaded part in Fig. 4 because the model structure is somewhat complicated to represent. The readers may refer to Nishida et al. (2004) for further details.

A model calculation by Nishida et al. (2004) proves that the above-mentioned enhancement of the secular changes originates in the piezomagnetic effect: the tectonic stress

Copyright (c) The Society of Geomagnetism and Earth, Planetary and Space Sciences (SGEPSS); The Seismological Society of Japan; The Volcanological Society of Japan; The Geodetic Society of Japan; The Japanese Society for Planetary Sciences; TERRAPUB caused by the Pacific plate motion has been applied to the highly magnetized rocks. In addition to this, the piezomagnetic modeling also suggests the highly magnetized rocks have a larger stress sensitivity of $8.5 \times 10^{-3} \mathrm{MPa}^{-1}$ (Nishida et al., 2004) than that of the ordinarily assumed value $\left(1 \sim 2 \times 10^{-3} \mathrm{MPa}^{-1}\right)$.

In the present paper, we examine the short-term magnetic changes related with the 26 September $2003 M 8.0$ Tokachi-oki earthquake and the 29 November 2004 M 7.1 Kushiro-oki earthquake at the AKS magnetic station (Figs. 1 and 2) situated in the large secular change region. We also make model calculations to forecast the piezomagnetic amplitudes caused by the $M 7.9$ and $M 8.5$ earthquakes which have been expected to occur along the southern Kurile trench in the future.

\section{Seismic Activities Related with the Subduction of the Pacific Plate}

$M 8$ class earthquakes along the southern Kuril-Japan trench show an episodic activity and have done heavy damage to the wide area of Hokkaido. The most recent episode started in 1952 and great earthquakes occurred successively along the Kuril-Japan trench as shown in Fig. 1. The focal mechanism of these earthquakes is the low-angle thrust faulting which represents slip between the oceanic and continental lithospheres. Thus, these are called plate-boundary earthquakes. The episodic activity has a recurrence interval of about 100 years (e.g. Utsu, 1972). In addition to these plate-boundary earthquakes, intra-plate earthquakes occurred in 1993 (M 7.5) and 1994 (M 8.2) as shown in Fig. 1. 
Table 1. Fault parameters of earthquake models used for the calculation of the piezomagnetic field changes.

\begin{tabular}{|c|c|c|c|c|c|c|c|c|c|c|}
\hline & $\begin{array}{l}\text { Lat } \\
\left({ }^{\circ}\right)\end{array}$ & $\begin{array}{c}\text { Lon } \\
\left({ }^{\circ}\right)\end{array}$ & $\begin{array}{c}L \\
(\mathrm{~km})\end{array}$ & $\begin{array}{c}W \\
(\mathrm{~km})\end{array}$ & $\begin{array}{c}\text { Depth } \\
(\mathrm{km})\end{array}$ & $\begin{array}{c}\text { Strike } \\
\left({ }^{\circ}\right)\end{array}$ & $\begin{array}{l}\text { Dip } \\
\left({ }^{\circ}\right)\end{array}$ & $\begin{array}{c}\text { Rake } \\
\left(^{\circ}\right)\end{array}$ & $\begin{array}{l}\text { Slip } \\
\text { (m) }\end{array}$ & $M$ \\
\hline $2003^{*}$ & 42.12 & 144.55 & 85.7 & 83.0 & 19.7 & 231 & 22 & 110 & 5.2 & 8.0 \\
\hline $2004^{*}$ & 42.91 & 145.40 & 22.2 & 18.3 & 44.3 & 212 & 26 & 87 & 2.1 & 7.1 \\
\hline $1894^{* *}$ & 42.5 & 146.0 & 200.0 & 100.0 & 15.0 & 240 & 14 & 90 & 2.4 & 7.9 \\
\hline \multirow[t]{2}{*}{$17^{\text {th }} c^{* * *}$} & 42.99 & 147.22 & 200.0 & 100.0 & 17.0 & 228 & 20 & 90 & 5.0 & \multirow{2}{*}{8.5} \\
\hline & 41.82 & 145.38 & 100.0 & 100.0 & 17.0 & 228 & 20 & 90 & 10.0 & \\
\hline
\end{tabular}

*: after Geograph. Surv. Inst. Jpn. (2006), ${ }^{* *}$ : after Tanioka et al. (2007), ${ }^{* * *}$ : after Satake et al. (2004).

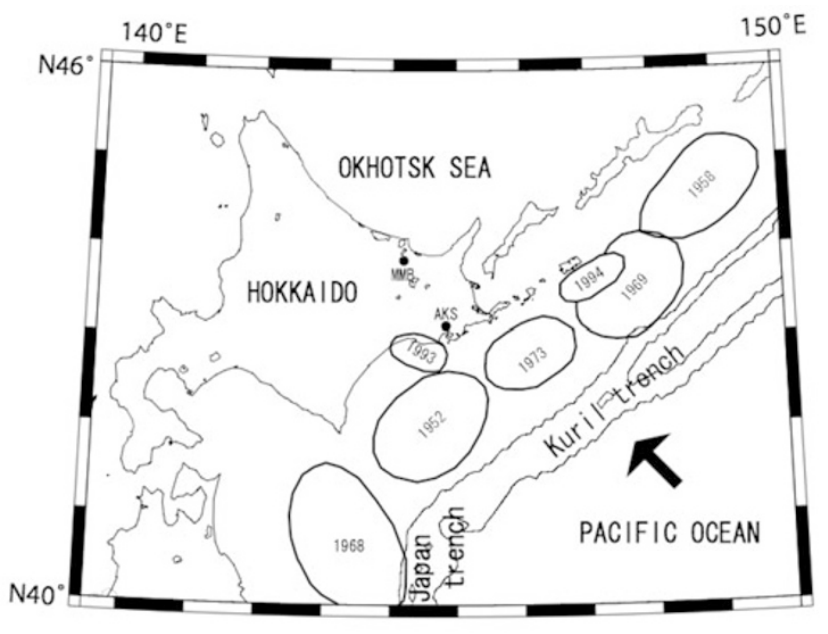

Fig. 1. Great and major earthquakes along the Kuril-Japan trench occurred in the $20^{\text {th }}$ centuries (modified after Kikuchi, 2003). A bold arrow indicates the direction of the Pacific plate motion. AKS shows a magnetic station while MMB (Memanbetsu Magnetic Observatory of the Japan Meteorological Agency) represents the reference station.

Succeeding to these earthquakes, two plate-boundary earthquakes occurred in 2003 and 2004 (Fig. 2). The slip distribution, estimated from tsunami wave forms, aftershock distributions and seismic wave forms, revealed that the whole area of the fault of the 2003 Tokachi-oki earthquake ( $M$ 8.0) overlapped only the western part of the fault plane of the 1952 Tokachi-oki earthquake ( $M$ 8.2), although the epicenter of the 2003 event was very close to that of the 1952 event (Tanioka et al., 2004). This suggests the eastern part of the fault plane of the 1952 event has potential to generate a large earthquake in the future. Co-seismic horizontal principal strain of the 2003 event was estimated by Ueda and Takahashi (2005) as about $(3 \sim 4) \times 10^{-6}$ around AKS, based on the GPS observations. The GPS observations also showed no detectable precursory displacement at stations located $70 \sim 240 \mathrm{~km}$ away from the epicenter, at least during 20 hours preceding the main shock (Irwan et al., 2004). The precursory strain change, if any, should be less than $10^{-7}$.

In the next year, the 2004 Kushiro-oki earthquake (M 7.1) occurred off the eastern part of Hokkaido (Katsumata and Yamanaka, 2006). Takahashi (personal communication) estimated the co-seismic strain as $(5 \sim 10) \times 10^{-7}$ around AKS. Any seismic and geodetic precursory signals were not found. The 2003 event probably triggered the 2004 event because the GPS data after the 2003 event have shown propagation of slow slip on the plate boundary to the east

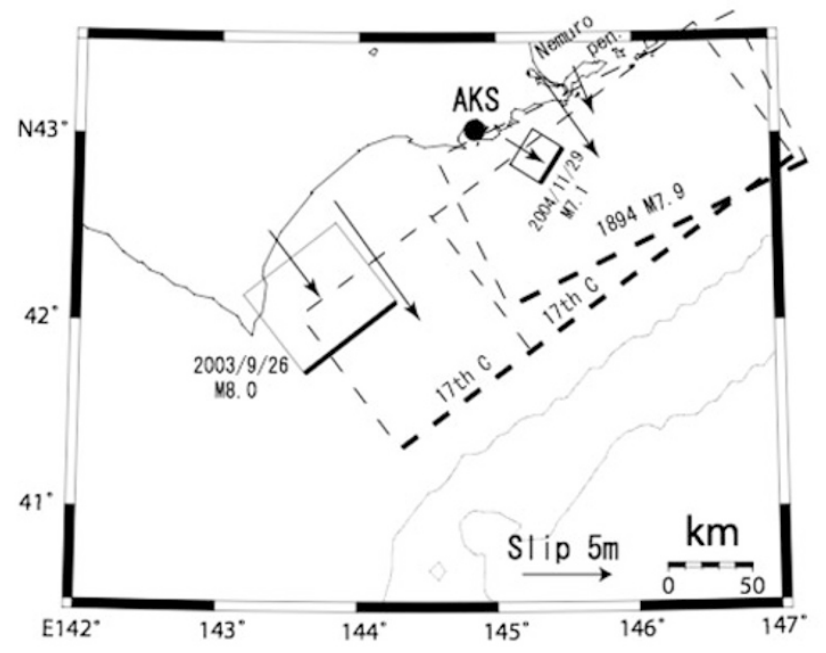

Fig. 2. The fault planes of the 2003 and 2004 events are projected onto the horizontal surface as shown by the solid squares, while those of the 1894 event and the $17^{\text {th }}$ century event are shown by dashed squares. For the $17^{\text {th }}$ century event, the fault plane is assumed to be subdivided into two parts; the eastern and western segments slipped $10 \mathrm{~m}$ and $5 \mathrm{~m}$, respectively, to generate the $M 8.5$ earthquake. Upper edges of the fault planes are shown by bold lines and dashes. Arrows represent the slip vector of the hanging wall.

(e.g. Murakami, 2005). Even after the 2004 event, the slow slip still proceeds and the eastern edge of slipping region migrates to the east, suggesting another earthquake will be triggered in the neighboring seismogenic region.

Fault parameters of the 2003 and the 2004 events estimated from the inversion of the seismic data are shown in Table 1 to use them as parameters for piezomagnetic modeling in the latter section.

\section{Magnetic Records}

After three and a half years' closing since 1999, we reopened the magnetic field observation at AKS on June, 2003. Measurement has been made by a proton precession magnetometer every 5 minutes with a sensitivity of $1 \mathrm{nT}$. Since then, we encountered two seismic events which occurred around the station in 2003 and 2004 as mentioned above: the epicentral distances from AKS to the 2003 and 2004 events are about $120 \mathrm{~km}$ and $50 \mathrm{~km}$, respectively.

We subtract magnetic field values at the reference station MMB (Memanbetsu Geomagnetic Observatory; Fig. 1) from the observed ones at AKS to discriminate the piezomagnetic signals at AKS. Figure 3 shows magnetic records for 24 hours including the occurrence time of the 2003 and 2004 events. The records shown by thin curves represent 
2004/11/29 3:32 M7. 1 Kushiro-oki Eq.

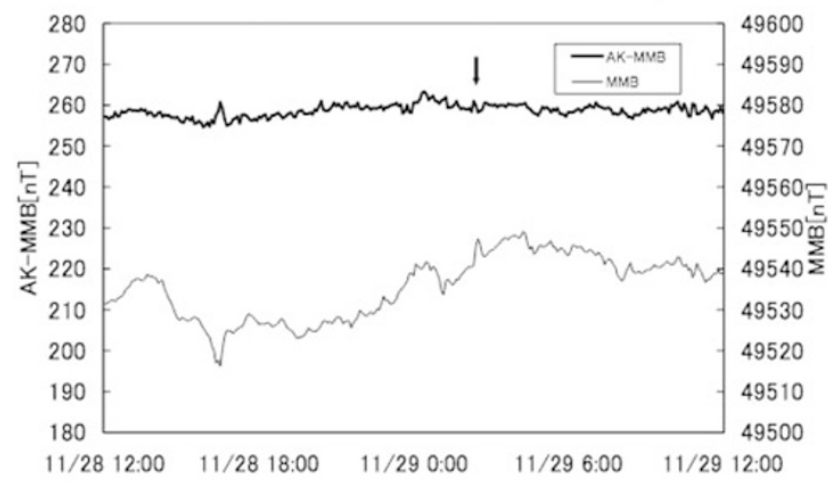

2003/9/26 4:50 M8. 0 Tokachi-oki Eq.

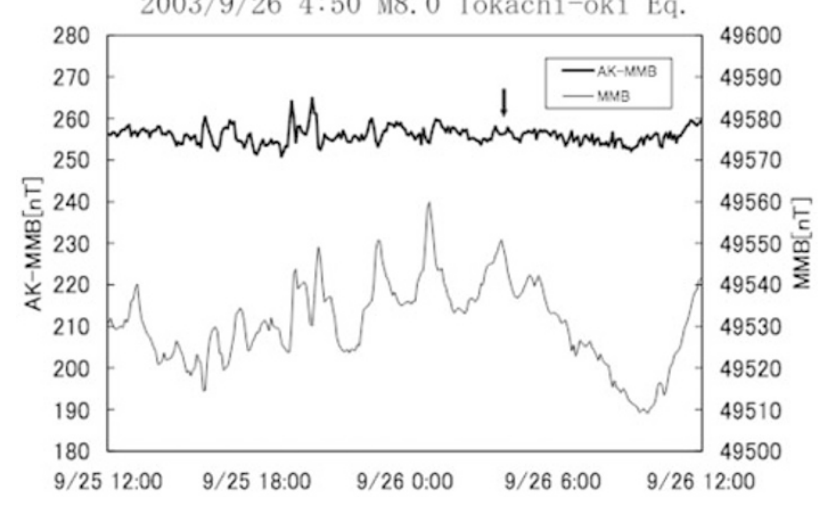

Fig. 3. Differences of the total force intensity between AKS and MMB (solid line) are shown for 24 hours before and after the 2003 and 2004 events. Raw data of the magnetic total fields at the reference station (MMB) (thin line).

raw data of the magnetic total fields at MMB to indicate the degree of the external field disturbances such as magnetic storms and diurnal variations. As the simple difference between two stations cannot completely remove the regional differences of the external field disturbances nor the local induced magnetic fields, which are independent from the piezomagnetic changes, we established corrected differences to extract the piezomagnetic signals using the Wiener filter method by Davis et al. (1979) and Davis et al. (1981) as shown by bold curves. Although the corrected differences do not eliminate perfectly the effect of the abovementioned regional differences as shown in Fig. 3, we cannot find clear manifestations of the short-term precursory and co-seismic signals, if any, above several nT in both cases. Then, to inspect the detectability of the piezomagnetic signals in both cases, we made model calculations as in the next section.

\section{Model Calculations}

Utsugi (1999, 2000) and Utsugi and Nishida (in preparation) have developed an analytical formula for the piezomagnetic potentials due to various types of pressure source within a non-uniformly magnetized medium. In order to represent the non-uniform distribution of the crustal magnetization, they assume that the crust is divided into a number of blocks and each block has its own magnetic properties, such as the magnetization and the stress sensitivity. The ge-

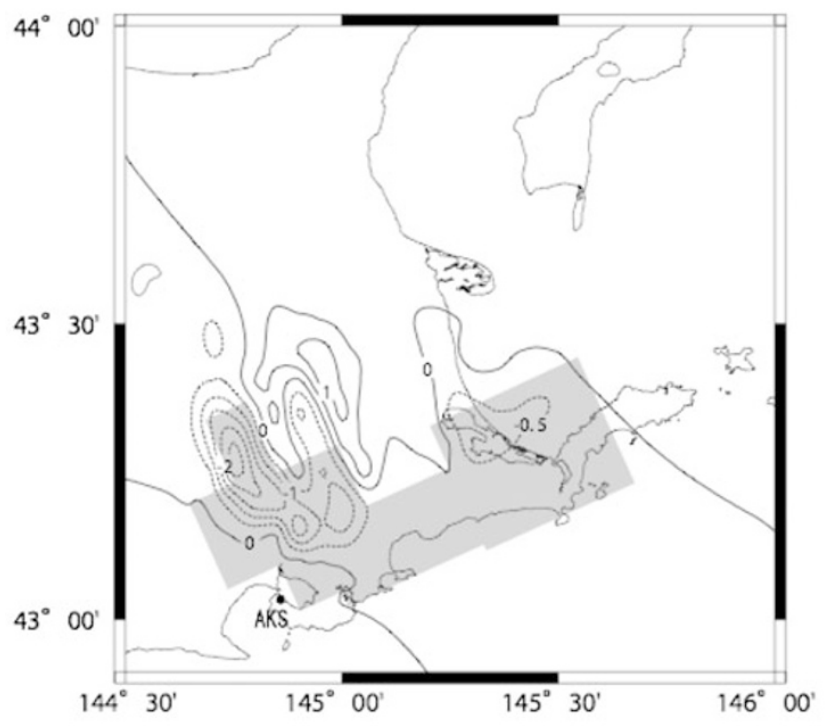

Fig. 4. Calculated piezomagnetic fields caused by the 2003 Tokachi-oki earthquake. Contour interval is $0.5 \mathrm{nT}$. Shaded part represents a horizontal projection of the calculated highly magnetized blocks in the upper crust (Nishida et al., 2004).

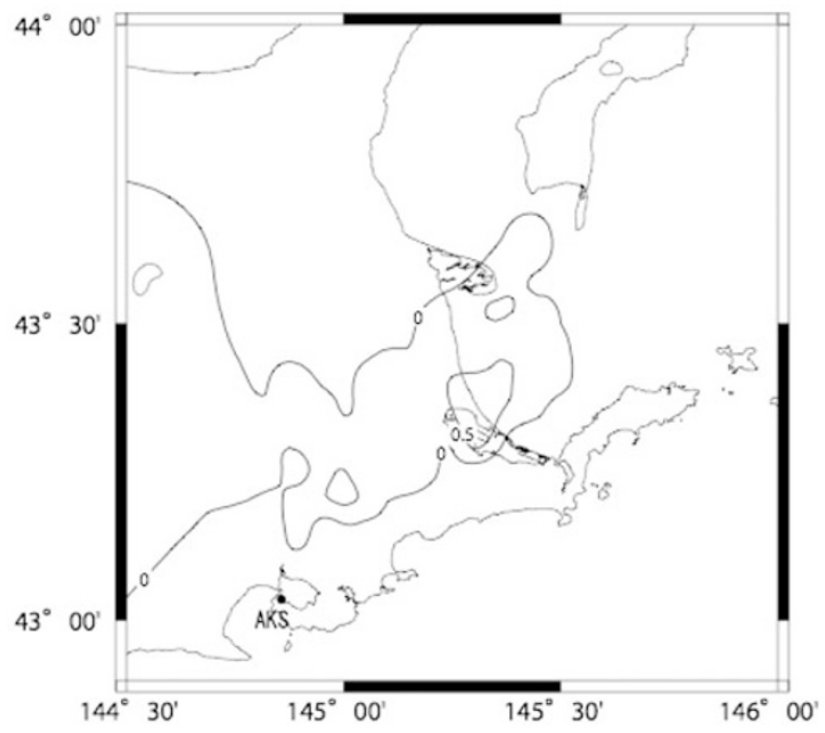

Fig. 5. Calculated piezomagnetic fields caused by the 2004 Kushiro-oki earthquake. Contour interval is $0.5 \mathrm{nT}$.

omagnetic field change at a certain point is approximated by the sum of the piezomagnetic fields derived from each block. The piezomagnetic potential $W_{k}$ due to a magnetized block is expressed by a definite surface integral over the boundary surface $S$ of the block (Sasai, 1991):

$$
\begin{aligned}
W_{k}\left(\boldsymbol{r}_{0}\right)= & C_{k} \iint_{S}\left[\left\{-\partial u_{k}(\boldsymbol{r}) / \partial n\right.\right. \\
& \left.+2(\lambda+\mu) /(3 \lambda+2 \mu) \Delta \boldsymbol{m}^{k} \cdot \boldsymbol{n}\right\}(1 / \rho) \\
& \left.+u_{k}(\boldsymbol{r})\{\partial / \partial n(1 / \rho)\}\right] d S,
\end{aligned}
$$

where

$$
\begin{aligned}
& C_{k}=1 / 2 \beta \mu J_{k}(3 \lambda+2 \mu) /(\lambda+\mu), \\
& \Delta \boldsymbol{m}^{k}=3 / 2\left(\partial u_{k} / \partial x_{l}+\partial u_{l} / \partial x_{k}\right)-\delta_{k l} \boldsymbol{\nabla} \cdot \boldsymbol{u} .
\end{aligned}
$$




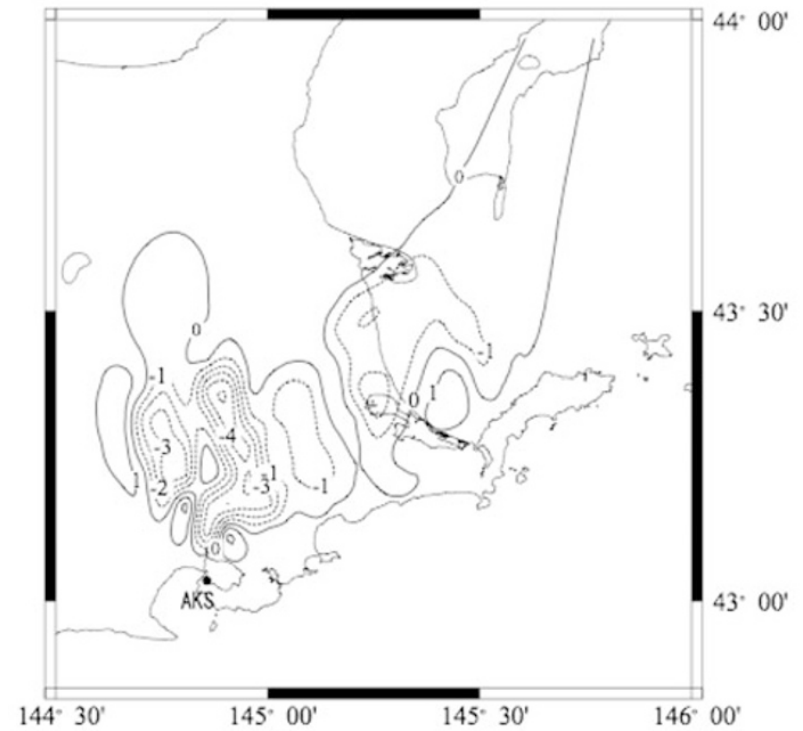

Fig. 6. Calculated piezomagnetic fields caused by the 1894 Nenuro-oki earthquake. Contour interval is $1 \mathrm{nT}$.

In the above, $k$ indicates the $k$-th Cartesian component and $\boldsymbol{n}$ an outward normal to the surface $S . \quad \delta_{k l}$ denotes the Kronecker delta and $\boldsymbol{u}$ is the displacement vector due to pressure source. $J_{k}$ means the $k$-th component of the rock magnetization. We denote $\rho$ as the distance between the location of the observation point $\boldsymbol{r}_{0}$ and the arbitrary point $\boldsymbol{r}$ on $S\left(\rho=\left|\boldsymbol{r}_{0}-\boldsymbol{r}\right|\right) . \beta$ is the stress sensitivity, and $\lambda$ and $\mu$ Lame's constants.

This definite surface integral cannot be solved analytically, in contrast with the indefinite integral as in the case of homogeneously magnetized half-space earth model (e.g., Sasai, 1991). However, Utsugi (1999, 2000) and Utsugi and Nishida (in preparation) show that an integral with respect to either coordinate $x_{i}(=x$ or $y$ or $z$ ) can be represented by an analytical form including elliptic integrals. Therefore, the surface integral over the block surface is reduced to the line integral. Through the numerical evaluations of the line integral, we can estimate the piezomagnetic field easily.

We calculated the co-seismic piezomagnetic fields for the 2003 and 2004 events, applying the above-mentioned method. In the calculations, we need some parameters such as the fault parameters, the Curie temperature depth, the magnetization of crustal rocks, and the stress sensitivity of rocks. Then, we assumed the fault parameters as shown in Table 1. In-situ Curie temperature depth was estimated by Okubo et al. (1989) as about $15 \mathrm{~km}$. The magnetic structure and the stress sensitivity are described in Section 1.

The calculated results are shown in Figs. 4 and 5 for the cases of the 2003 and 2004 events, respectively. In the case of the 2003 Tokachi-oki earthquake of $M 8.0$, we have small piezomagnetic signals of a few nT around the highly magnetized region, but the nodal line of the positive and negative signals runs near AKS. In the case of the 2004 Nemuro-oki earthquake of $M 7.1$, we can expect only sub-nT changes at the maximum on land. Therefore, it is reasonable that we could not detect the piezomagnetic signals at AKS.

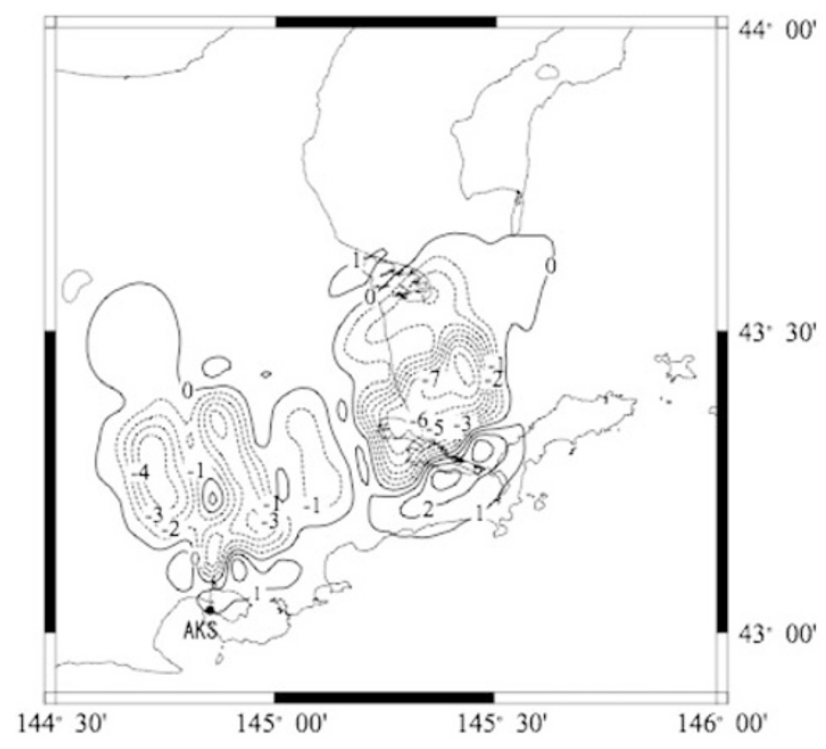

Fig. 7. Calculated piezomagnetic fields caused by the $17^{\text {th }}$ century earthquake. Contour interval is $1 \mathrm{nT}$.

Calculated piezomagnetic fields for the 2003 event amount to the maximum amplitude of about $-2 \mathrm{nT}$ in an area to the north of AKS, which should have been detectable by our observation system. Unfortunately, however, we had closed a station around there (station KKM in Nishida et al., 2004).

\section{Piezomagnetic Fields Caused by Expected-to- occur Earthquakes}

As described in Section 2, migration of the slow slip after the 2003 event suggests another earthquake will be triggered in the neighboring seismogenic region. This predicted earthquake is hypothesized to occur off the Nemuro peninsula where the $M 7.9$ earthquake occurred in 1894 (Fig. 2) because the 1973 M 7.4 earthquake taken place off the Nemuro peninsula released only a part of the strain energy accumulated there (Shimazaki, 1974). Headquarters for Earthquake Research Promotion (2003) presents the probability whether the predicted earthquake occurs within these 30 years as about $30 \%$ and anticipates the energy release of about two times as much as the 1973 event. The fault model is estimated as low-angle thrust faulting by Tanioka et al. (2007) as shown in Fig. 2 and Table 1, based on the tsunami records of the 1894 event.

In addition to the above-mentioned expected-to-occur earthquake off the Nemuro peninsula, traces of prehistoric and historic tsunami deposits in the eastern part of Hokkaido have revealed unusually large tsunamis occurred about every 300 500 years on average over the past $2,000 \sim 7,000$ years, most recently about 350 years ago (the $17^{\text {th }}$ century), suggesting occurrence of a great earthquake of $M 8.5$ in the present century (Hirakawa et al., 2000; Nanayama et al., 2003). As it is difficult to predict the detailed seismic parameters at present, we hypothesize that the unusual tsunami earthquake of $M 8.5$ will come again in the future. Satake et al. (2004) proposed an optimal seismic source model shown in Fig. 2 and Table 1 to reproduce 
tsunami heights along the Hokkaido coast which were deduced from tsunami deposits: a low-angle thrust faulting with uniform $10 \mathrm{~m}$ slip of the western segment and uniform $5 \mathrm{~m}$ slip of the eastern segment may occur simultaneously along the Kuril-Japan trench axis to generate the $M 8.5$ earthquake.

We made model calculations to forecast the piezomagnetic amplitude caused by these two extected-to-occur earthquakes. Necessary parameters for the calculation, such as the Curie temperature depth, the subsurface magnetic structure and the stress sensitivity, are common to those described in Section 4.

The model calculations give the piezomagnetic fields up to about $-4 \mathrm{nT}$ and $-7 \mathrm{nT}$ in the eastern part of Hokkaido (Figs. 6 and 7) for the $M 7.9$ and $M 8.5$ earthquakes, respectively. We notice that the piezomagnetic field tends to be enhanced around the margin of the strongly magnetized blocks as seen typically in Fig. 4. Such enhancement is explained by the fact that magnetic fields arising from the stress-induced magnetization tend to cancel one another within a uniformly magnetized block, while they do not at the boundary between the strongly and weakly magnetized mediums (Oshiman, 1990; Utsugi, 1999, 2000).

\section{Discussion and Conclusion}

We could not find significant magnetic signals related with the 2003 Tokachi-oki earthquake and the 2004 Kushiro-oki earthquake at the AKS station. Model calculations showed that co-seismic piezomagnetic fields did not amount to $1 \mathrm{nT}$ at AKS in both cases despite the use of the strong magnetization and high stress sensitivity of the rocks around the station. The results may be due to too long hypocentral distances despite the large earthquake magnitudes.

A model calculation for an expected-to-occur earthquake of $M 7.9$ off the Nemuro peninsula shows the co-seismic magnetic change up to about $-4 \mathrm{nT}$ in the eastern part of Hokkaido. Another model calculation also reveals the coseismic magnetic field change up to about $-7 \mathrm{nT}$ for an expected-to-occur earthquake of $M 8.5$.

The results would be of much help for us to design the optimal arrangement of magnetometers to detect the coseismic signals. Considering the forecasted piezomagnetic amplitudes, we re-opened the magnetic stations at NEM, SHI, NIT and NIB as well as AKS shown in Nishida et al. (2004). In addition, we newly established 3 stations at OBT $\left(\mathrm{N} 43^{\circ} 07^{\prime} 35.5^{\prime \prime}\right.$; E144 $\left.46^{\prime} 23.3^{\prime \prime}\right)$ and HTU (N43 $11^{\prime} 17.7^{\prime \prime}$; $\left.\mathrm{E} 145^{\circ} 18^{\prime} 43.8^{\prime \prime}\right)$ on June, 2006 and at BEK (N43 $20^{\prime} 12.8^{\prime \prime}$; E145 $10^{\prime} 50.3^{\prime \prime}$ ) on June, 2007.

However, rough estimates show a small amount of precursory piezomagnetic signals, say only less than $0.1 \mathrm{nT} / \mathrm{year}$, on land stations when we assume the linear accumulation of the strain caused by the Pacific plate motion during these about 80 years recurrence-interval for the Nemuro peninsula earthquake and 350 years for reappearance of the $17^{\text {th }}$ century earthquake. It would be difficult to discriminate precursory signals of piezomagnetic origin through our current system of observation (sensitivity of $1 \mathrm{nT}$ ) and we need more improved observations: for example, we approach the epicentral region through ocean bot- tom observations to detect more amplified signals (Utsugi, 1999; Utsugi and Nishida, in preparation) and/or try other attempts such as magnetic observations within boreholes at appropriate places on land because magnetic poles are expected to emerge along the wall of the borehole to enhance the piezomagnetic signals as predicted theoretically by Sasai $(1994,2001)$ and Sasai et al. (2007).

Acknowledgments. We thank Minoru Kasahara, Hiroaki Takahashi, Yoshikazu Tanaka and Masayoshi Ichiyanagi who have supported this study. We also thank staffs at Memanbetsu Geomagnetic Observatory of the Japan Meteorological Agency (JMA) for providing magnetic records. Gratitude is expressed to Takeshi Hashimoto and Masamitsu Takada and Akkeshi Marine Station of Hokkaido University for their great efforts in the field work. Yoichi Sasai and Kenichi Yamazaki provided useful review comments to complete the manuscript.

\section{References}

Davis, P. M., F. D. Stacey, C. J. Zablocki, and J. V. Olson, Improved signal discrimination in tectonomagnetism: discovery of a volcanomagnetic effect at Kilauea, Hawaii, Phys. Earth Planet. Inter., 19, 331-336, 1979.

Davis, P. M., D. D. Jackson, C. A. Searls, and R. L. McPherron, Detection of tectonomagnetic events using multichannel predictive filtering, $J$. Geophys. Res., 86, 1731-1737, 1981.

Geographical Survey Institute of Japan, Crustal deformation caused by the recent seismic activities, http://cais.gsi.go.jp/HENDOU/hendou.html/, 2006.

Headquarters for Earthquake Research Promotion, Long-term evaluation of seismic activities along the Kuril trench, http://www.jishin.go.jp/ main/index.html, 2003 (in Japanese).

Hirakawa, K., Y. Nakamura, and T. Echigo, Large paleo-tsunamis along the Pacific coast of Tokachi region, Hokkaido, Chikyu Monthly, special issue, 31, 92-98, 2000 (in Japanese).

Irwan, M., F. Kimata, K. Hirahara, T. Sagiya, and A. Yamagiwa, Measuring ground deformation with 1-Hz GPS data: the 2003 Tokachioki earthquake (preliminary report), Earth Planets Space, 56, 389-393, 2004.

Katsumata, K. and Y. Yamanaka, The 29 November 2004 M7.1 Kushirooki earthquake; An event between the on-going seismic quiescence area and the asperity ruptured by the 1973 Nemuro-oki earthquake, Geophys. Bull. Hokkaido Univ., 69, 23-39, 2006 (in Japanese with English abstract).

Kikuchi, M., Realtime seismology, Univ. Tokyo Press, p. 222, Tokyo, 2003 (in Japanese).

Murakami, M., Slow slip on the plate boundary offshore eastern Hokkaido Japan along Kuril trench since the occurrence of M8.0, 2003 Tokachioki earthquake, in Abstracts of the Seismol. Soc. Jpn., 2005 Fall Meeting, 29, 2005.

Nanayama, F, K. Satake, R. Furukawa, K. Shimokawa, B. F. Atwater, K. Shigeno, and S. Yamaki, Unusually large earthquakes inferred from tsunami deposits along the Kuril trench, Nature, 424, 660-663, 2003.

Nishida, Y., Y. Sugisaki, K. Takahashi, M. Utsugi, and H. Oshima, Tectonomagnetic study in the eastern part of Hokkaido, NE Japan: Discrepancy between observed and calculated results, Earth Planets Space, 56, 1049-1058, 2004.

Okubo, Y., H. Tsu, and K. Ogawa, Estimation of Curie point temperature and geothermal structure of island arcs of Japan, Tectonophys., 159, 279-290, 1989.

Oshiman, N., Enhancement of tectonomagnetic change due to non-uniform magnetization in the Earth's crust-two dimensional case studies, $J$. Geomag. Geoelectr., 42, 607-619, 1990.

Sasai, Y., Tectonomagnetic modeling on the basis of the linear piezomagnetic effect, Bull. Earthq. Res. Inst., Univ. Tokyo, 66, 585-722, 1991.

Sasai, Y., Enhancement of piezomagnetic signals within a bore-hole, in Electromagnetic Phenomena Related to Earthquake Prediction, edited by M. Hayakawa and Y. Fujinawa, 51-54, TERRAPUB, Tokyo, 1994.

Sasai, Y., Tectonomagnetic modeling on the piezomagnetism: a review, Annali di Geofisica, 44, 361-368, 2001.

Sasai, Y., M. J. S. Johnston, Y. Tanaka, R. Mueller, T. Hashimoto, M. Utsugi, S. Sakanaka, M. Uyeshima, J. Zlotnicki, and P. Yvetot, Dragout effect of piezomagnetic signals due to a borehole: The Mogi source 
as an example, Annals of Geophysics., 50, 93-104, 2007.

Satake, K., F. Nanayama, and S. Yamaki, Source models of the unusual tsunami in the $17^{\text {th }}$ century in eastern Hokkaido: part 2, Rep. Active Fault and Paleoseismic Study, 4, 17-29, 2004 (in Japanese with English abstract).

Simazaki, K., Nemuro-oki earthquake of June 17, 1973: A lithospheric rebound at the upper half of the interface, Phys. Earth Planet. Inter., 9, 314-327, 1974.

Tanioka, Y., K. Hirata, R. Hino, and T. Kanazawa, Slip distribution of the 2003 Tokachi-oki earthquake estimated from tsunami waveform inversion, Earth Planets Space, 56, 373-376, 2004.

Tanioka, Y., K. Satake, and K. Hirata, Recurrence of recent large earthquakes along the most southern part of Kurile-Kamchtka subduction zone, AGU Monoghraph, 2007 (in press).

Ueda, M. and H. Takahashi, Triggered earthquakes along the volcanic front in the eastern Hokkaido, Japan, and its relevance to the static stress change, Zisin (J. Seismol. Soc. Jpn.), 58, 115-119, 2005 (in Japanese). Utsu, T., Large earthquakes near Hokkaido and the expectation of the occurrence of a large earthquake off Nemuro, Rep. Cord, Community Earthquake Prediction, 7, 7-13, 1972 (in Japanese).

Utsugi, M., A theoretical study on seismomagnetic effect considering the inhomogeneously magnetized Earth's crust, Ph.D. Thesis, Hokkaido Univ., pp.128, 1999.

Utsugi, M., A computer program for the calculation of piezomagnetic field due to a spherical source (Mogi model) in the inhomogeneously magnetized crust, J. Fac. Sci., Hokkaido Univ., Ser. 7, 11, 739-751, 2000 .

Y. Nishida (e-mail: nishida@ares.sci.hokudai.ac.jp), M. Utsugi, and T. 